\title{
Hemi-Castaing ligamentoplasty for the treatment of chronic lateral ankle instability: a retrospective assessment of outcome
}

\author{
Tim Schepers $•$ Lucas M. M. Vogels • \\ Esther M. M. Van Lieshout
}

Received: 30 April 2011 / Accepted: 17 May 2011 /Published online: 3 June 2011

(C) The Author(s) 2011. This article is published with open access at Springerlink.com

\begin{abstract}
Purpose In the treatment of chronic ankle instability, most non-anatomical reconstructions use the peroneus brevis tendon. This, however, sacrifices the natural ankle stabilising properties of the peroneus brevis muscle. The aim of this study was to evaluate the functional outcome of patients treated with a hemi-Castaing procedure, which uses only half the peroneus brevis tendon.

Methods We performed a retrospective cohort study of patients who underwent hemi-Castaing ligamentoplasty for chronic lateral ankle instability between 1993 and 2010, with a minimum of one year follow-up. Patients were sent a postal questionnaire comprising five validated outcome measures: Olerud-Molander Ankle Score (OMAS), Karlsson Ankle Functional Score (KAFS), Tegner Activity Level Score (pre-injury, prior to surgery, at follow-up), visual analog scale on pain (VAS) and the Short Form 36 (SF-36).

Results Twenty patients completed the questionnaire on functional outcome. The OMAS showed good to excellent outcome in $80 \%$ and the KAFS in $65 \%$, the Tegner Score improved from surgery but did not reach pre-injury levels, the VAS on pain was 1 of 10 and the SF-36 returned to normal compared with the average population.

Conclusions Even though most patients were satisfied with the results, outcome at long-term follow-up was less favourable compared with the literature on anatomical reconstructions. In accordance with the literature, we therefore conclude that the initial surgical treatment of chronic lateral ankle instability should be an anatomical repair with
\end{abstract}

T. Schepers $(\bowtie) \cdot$ L. M. M. Vogels • E. M. M. Van Lieshout Department of Surgery-Traumatology, Erasmus MC,

University Medical Center Rotterdam,

Room H-822k, P.O. Box 2040, 3000 CA Rotterdam,

The Netherlands

e-mail: t.schepers@erasmusmc.nl augmentation (i.e. the Broström-Gould technique) and the non-anatomical repair should be reserved for unsuccessful cases after anatomical repair or in cases where no adequate ligament remnants are available for reconstruction.

\section{Introduction}

It has been estimated that more than 80 techniques exist for the treatment of lateral ankle instability $[16,18]$. One of the earliest ideas was to prevent chronic instability from happening by early suturing of the acutely ruptured ligaments; currently, this management strategy is no longer in use [26]. Nowadays, most agree to perform surgery in the $15-40 \%$ of patients with recurrent instability who are hampered in daily or sporting activities [4, 7, 37].

Overall the surgical treatment modalities for recurrent or chronic lateral ankle instability are divided into (1) direct anatomical repairs (ligament suturing), (2) non-anatomical (tendon rerouting procedures without suturing native ligaments) and (3) augmented anatomical procedures (combination of procedures) [18, 51]. Recommendations from a recent review were to perform a direct repair with or without augmentation as the primary intervention and save ligamentoplasty as a secondary procedure [34]. However, those favouring a ligamentoplasty claim more stability compared with an anatomical repair and frequently no adequate ligamentous structures are available for a direct repair $[13,18]$. The peroneus brevis is the most frequently used tendon for a tenodesis in the treatment of lateral ankle instability [17]. In 1984, Castaing described a ligamentoplasty technique for the treatment of chronic lateral ankle instability, using the entire peroneus brevis tendon $[9,21]$. Later it was shown that using a split tendon provides better overall results compared with the use of the entire tendon 
[34]. The hemi-Castaing procedure is a form of split peroneus tendon tenodesis, which has been infrequently reported in the literature [33, 34, 47]. The benefit of a hemiCastaing is the preservation of the natural ankle stabilising properties of the peroneus brevis muscle.

The primary objective of this study was to determine the long-term functional outcome in patients who underwent a hemi-Castaing ligamentoplasty for chronic lateral instability of the ankle.

\section{Patients and method}

This study is a retrospective cohort study in adult patients (age 18 years or over) who underwent hemi-Castaing ligamentoplasty for the treatment of chronic lateral ankle instability. All patients were treated between the years 1993 and 2010. Only patients with a minimum of one year follow-up were included. Since 1993, the hemi-Castaing ligamentoplasty has been the favoured operative treatment for these injuries in our department. Chronic lateral ankle instability was defined as recurrent ankle sprains, instability, and 'giving way' for at least six months after conservative treatment of an ankle inversion trauma. Physical examination included the anterior drawer test and the inversion or talar tilt test to assess the integrity of the anterior talofibular ligament (ATFL) and the calcaneofibular ligament (CFL). Stress radiographs taken with the Telos device, or magnetic resonance imaging (MRI), were performed only when deemed necessary. The local Medical Ethics Board approved the study, and informed consent was obtained from all patients.

\section{Surgical technique}

All operations were performed by or under the supervision of the same surgeon. The principle of most non-anatomical ligamentoplasties is to use the tendon of the peroneus brevis muscle. Due to its position and inherent strength of its distal anchor point, this complete tendon is used to strengthen the lateral ankle joint in the ligamentoplasty initially described by Castaing et al. [9]. The modification used in this study of this tenodesis, named the hemiCastaing or Castaing II, makes use of half the peroneus brevis tendon. Hemi-Castaing ligamentoplasty begins with an incision over the lateral ankle, exposing the lateral malleolus and tendon of the peroneus brevis muscle (Fig. 1a), approximately $15 \mathrm{~cm}$ from its point of insertion. The tendon is hemi-sected proximally for half of its diameter and then split over the length of the tendon to the level of the most distal point of the fibula, releasing an $8-\mathrm{cm}$ cord of tendon, free proximally, but remaining firmly anchored at its point of insertion at the base of the fifth metatarsal, the so-called hemi-tendon (Fig. 1b). A hole is then drilled through the distal part of the lateral malleolus, forming a tunnel. The direction of the tunnel runs between the directions of the ATFL and CFL (Fig. 1c). The hemitendon is passed through the tunnel from back to front and sutured to itself distally. The foot is maintained in a neutral anatomical position while the sutures are progressively tightened until optimal tensioning is reached (Figs. 1d and 2) [9]. Postoperatively patients are kept in non-weightbearing plaster for two weeks and weight-bearing plaster for six weeks.

\section{Outcome assessment}

Patients were sent a postal questionnaire comprising five validated outcome measures. Intrinsic, injury- and intervention-related variables as well as data on intra- and postoperative complications and secondary interventions were taken from the (electronic) patient files.

The primary outcome measure was the Olerud-Molander Ankle Score (OMAS), which is a validated, self-administered questionnaire [41]. The scale is a functional rating scale from 0 (totally impaired) to 100 (completely unimpaired) and is based upon nine different items: pain, stiffness, swelling, stair climbing, running, jumping, squatting, supports and activities of daily living [41]. The OMAS has been frequently used to evaluate subjectively scored function after chronic ankle instability treatment. Outcome was categorised into four groups: excellent (91-100 points), good (61-90 points), fair (31-60 points) or poor (0-30 points).

Secondary outcome measures were the Karlsson Ankle Functional Score (KAFS), the Tegner Activity Level Score pre- and post-injury, pain and quality of life. The KAFS is a validated disease-specific measure that was developed for individuals who have sustained a lateral ankle injury [25]. This scale contains eight items covering content related to instability, pain, swelling, stiffness, functional activities (i.e. stair climbing, running and work activities) and need for support. Values for each of these items are summed, with a higher score representing a higher level of function. Results are classified with four different outcomes: outcome was categorised into four groups: excellent (90-100 points), good (80-89 points), fair $(60-79$ points) or poor $(\leq 60$ points) [25].

The Tegner Activity Level Score was designed as a score of activity level to complement other functional scores for patients with ligamentous injuries [50]. The instrument scores a person's activity level between 0 and 10 where 0 is 'on sick leave/disability' and 10 is 'participation in competitive sports such as soccer at a national or international elite level'. It is the most widely used activity scoring system for patients with ankle disorders. The score has been validated for use in patients with ankle instability [50]. 
Fig. 1 Hemi-Castaing surgical procedure. Details on the operation are given in the "Surgical technique" section
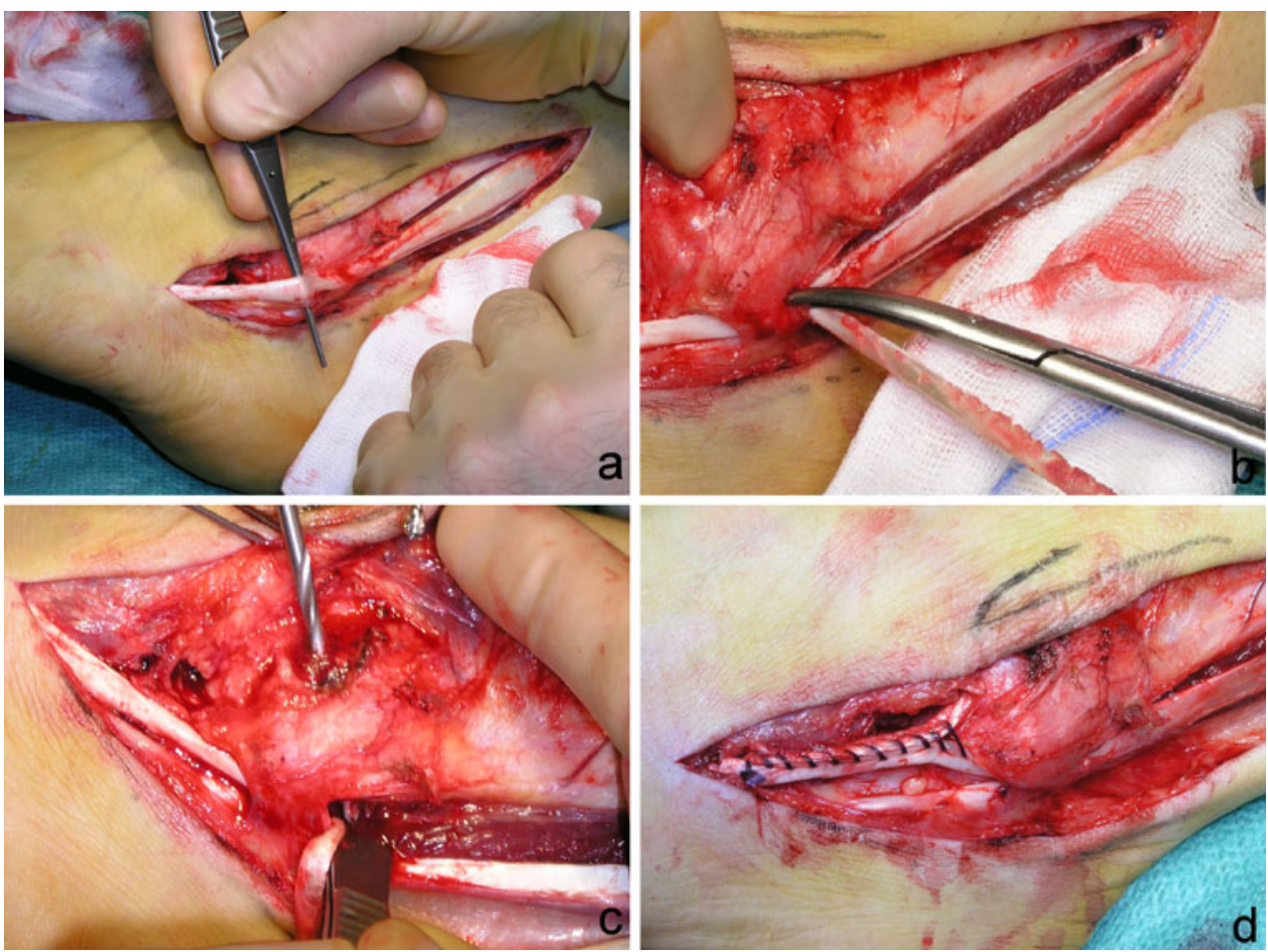

Pain level on both sides was determined using a 10-point visual analog scale (VAS), in which 0 implied no pain and 10 implied the worst possible pain.

The Short Form 36 (SF-36) is a validated multipurpose, short-form health survey with 36 questions, representing eight health domains that are combined into a physical and a mental component scale [53]. Scores ranging from 0 to 100 points are derived for each domain, with lower scores indicating poorer function. These scores were converted to a norm-based score and compared with the norms for the general population of the USA (1998; Dutch norm-based scores are not available), in which each scale was scored to
Fig. 2 MRI view of ankle following hemi-Castaing procedure. Distal fibula with peroneus brevis loop: a T1weighted image, b T2-weighted image
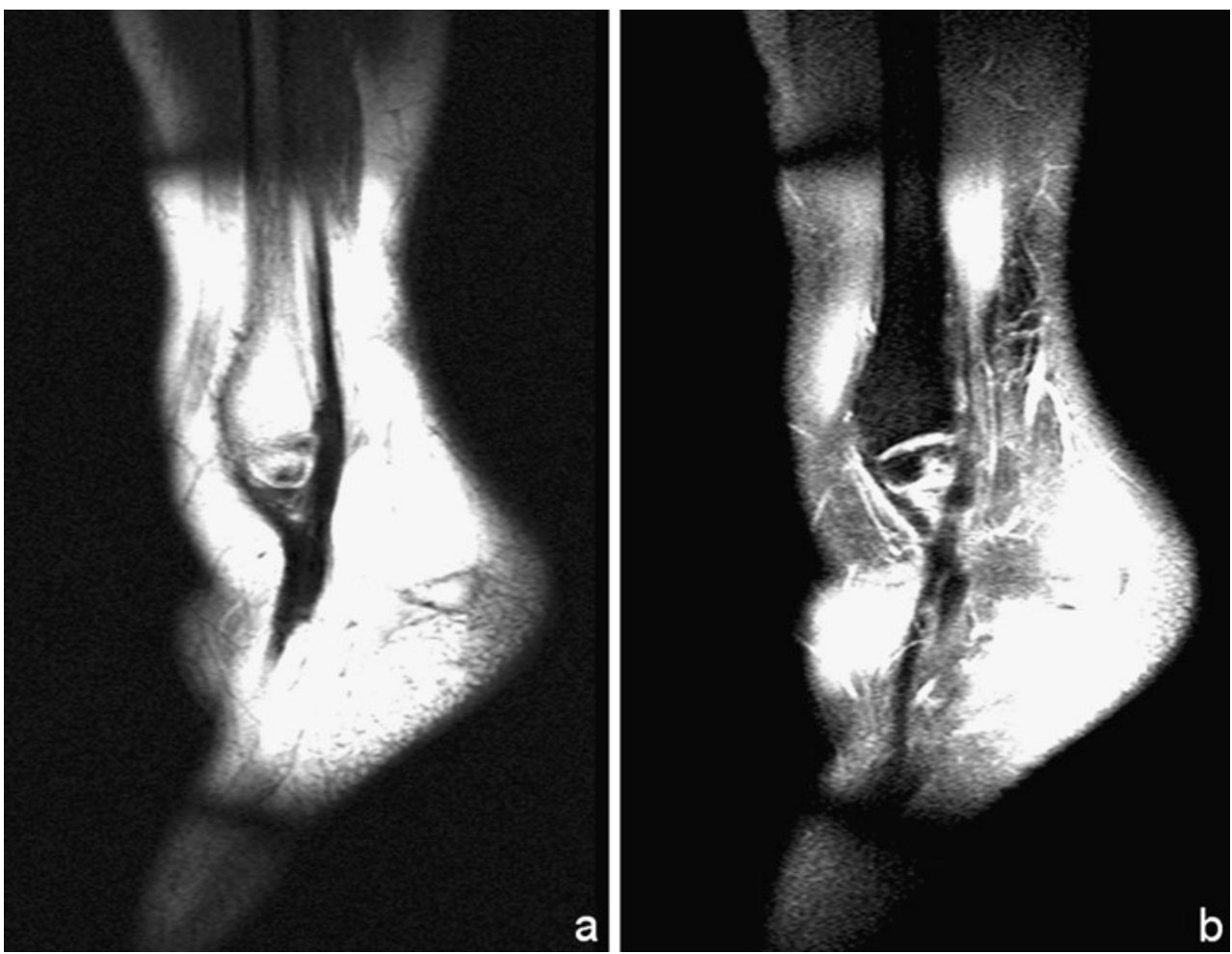
have the same average (50 points) and the same standard deviation (10 points).

\section{Statistical analysis}

Data were analysed using the Statistical Package for the Social Sciences (SPSS) version 16.0 (SPSS, Chicago, IL, USA). Normality of continuous data was tested with the Shapiro-Wilk test. Descriptive analysis was performed in order to describe baseline characteristics (intrinsic, injuryand intervention-related variables) and outcome measures. For continuous data the mean $\pm \mathrm{SD}$ (parametric data) or medians and percentiles (non-parametric data) were calculated. For categoric data percentages were calculated. A multivariable linear regression analysis was performed in order to model the relation between different covariates and the OMAS score. Intrinsic, injury- and intervention-related variables were added as covariates. Similar models were made to model the relation between covariates and the other numeric outcome measures.

\section{Results}

Between January 1993 and March 2010 a total of 26 patients were treated for 30 chronically unstable ankles with the hemi-Castaing technique. Of the 26 patients, one died approximately two years after surgery from an unrelated cause and five patients were lost to follow-up due to unknown addresses, leaving 20 patients available at followup (Table 1).

There were 12 male and eight female patients. The median age at surgery was 35.1 years $\left(\mathrm{P}_{25}-\mathrm{P}_{75} 23.4-42.1\right)$. The right side was affected eight times, the left 11 times and one patient had bilateral treatment. The average duration of complaints before surgery was $28.3 \pm 12.0$ SEM months, and the average number of recurrent sprains per month prior to the operation was $36 \pm 20$ SEM. Two patients had mild arthritic changes at the ankle joint prior to surgery. Eleven patients $(55 \%)$ were smokers at the time of the operation. One patient had undergone a Broström procedure prior to the hemi-Castaing ligamentoplasty and one patient had a loose body removed from the ankle joint at the time of the ligamentoplasty.

The median duration of follow-up was 92.9 months $\left(\mathrm{P}_{25}-\mathrm{P}_{75} 73.5-185.0\right)$ and the median age at follow-up was 42.0 years $\left(\mathrm{P}_{25}-\mathrm{P}_{75} 35.8-49.6\right)$. One patient suffered from a re-rupture after significant supination trauma and had a second Hemi-Castaing using the remainder of the peroneus brevis tendon almost three years after the index operation. Two patients had an arthroscopy to remove a loose body.

The median OMAS was 90 points $\left(\mathrm{P}_{25}-\mathrm{P}_{75} 73-100\right)$ and $80 \%$ achieved a good or excellent outcome. The median
KAFS was 88 points $\left(\mathrm{P}_{25}-\mathrm{P}_{75}\right.$ 61-100), with $65 \%$ achieving a good or excellent outcome. The VAS for pain was $1\left(\mathrm{P}_{25}-\mathrm{P}_{75} 0-4\right)$, compared with 0 for the contralateral side. None of these three outcome scores was significantly influenced by age, duration of follow-up, gender, side, smoking or arthrosis. The Spearman rank test showed a strong correlation between the OMAS, KAFS, VAS, Physical Component Scale (PCS) and SF-36 total score $(p<0.001)$. The Mental Component Scale (MCS) did not correlate with any of the other scores.

The median Tegner Score before complaints, before surgery and currently were $7\left(\mathrm{P}_{25}-\mathrm{P}_{75} 4-9\right), 3\left(\mathrm{P}_{25}-\mathrm{P}_{75} 1-8\right)$ and $4\left(\mathrm{P}_{25}-\mathrm{P}_{75} 2-7\right)$, respectively. Considering the SF-36 the PCS was 54.2 $\left(\mathrm{P}_{25}-\mathrm{P}_{75}\right.$ 45.7-57.2), the MCS was 59.4 $\left(\mathrm{P}_{25}-\mathrm{P}_{75}\right.$ 54.2-62.1) and the total SF-36 score reached $109.5\left(\mathrm{P}_{25}-\mathrm{P}_{75}\right.$ 102.1-117.1). For all eight domains of the SF-36 score, the median score was slightly higher than the normalised population score of 50 points (Fig. 3). Considering instability at follow-up, three patients $(15 \%)$ reported using a brace or tape on some occasions (patients 16, 17 and 18). One patient (case 20), whose radiographs already showed arthrosis at the ankle joint prior to the hemi-Castaing, scored poor on all outcome scores and was offered a tibiotalar arthrodesis.

\section{Discussion}

Data on outcome after the surgical treatment of chronic lateral ankle instability using the hemi-Castaing procedure are scarce. In this study, at a mean follow-up of 7.74 years, a good to excellent outcome was obtained in $65 \%$ with the KAFS to $80 \%$ using the OMAS.

The median OMAS was 90 points. Muijs et al. applied the OMAS in 24 patients treated with a Duquennoy procedure, with a follow-up of 13 years, reaching an average score of 82 points and $81 \%$ good to excellent outcome [37]. Ibrahim et al. treated 14 patients with an anatomical gracilis plasty and found an OMAS of 88 after almost three years follow-up. In our study the median KAFS was 88 points with $65 \%$ reaching a good or excellent outcome. In the literature on non-anatomical reconstructions, median KAFS scores between 67 and 95 points have been published [28, 30, 49, 54]. Good to excellent outcome varies from 33 to $100 \%$ in recent studies with peroneus brevis ligamentoplasty and a minimum of five years followup $[27,28,30,34,39]$. It is noteworthy that the highest outcome scores are obtained in the smallest groups [49, 54].

No outcome data for the Tegner Score in the hemiCastaing procedure are available. Morelli et al. reported a Tegner Score of 6.8 pre-surgery and 5.1 after a modified Watson-Jones procedure [36]. This post-surgery score was slightly higher than the Tegner Score of 4 which was found 
Table 1 Patient characteristics and outcome data of patients treated using a hemi-Castaing

\begin{tabular}{|c|c|c|c|c|c|c|c|c|c|c|c|c|}
\hline Patient & Gender & Age & FU (months) & Side & OMAS & KAFS & Tegner pre-injury & Tegner preoperative & Tegner FU & SF-36 & VAS & Stiffness \\
\hline 1 & M & 35 & 80 & $\mathrm{~L}$ & 100 & 100 & 10 & 10 & 8 & 109 & 1.0 & No \\
\hline 2 & $\mathrm{~F}$ & 39 & 26 & $\mathrm{R}$ & 100 & 100 & 7 & 6 & 3 & 118 & 0.0 & No \\
\hline 3 & $\mathrm{~F}$ & 25 & 89 & $\mathrm{~L}$ & 90 & 100 & 10 & 1 & 7 & 116 & 0.0 & No \\
\hline 4 & M & 38 & 98 & $\mathrm{R}$ & 100 & 95 & 8 & 1 & 6 & 117 & 0.0 & No \\
\hline 5 & $\mathrm{~F}$ & 39 & 73 & $\mathrm{~L}$ & 95 & 95 & 1 & 0 & 1 & 118 & 0.0 & No \\
\hline 6 & M & 22 & 214 & $\mathrm{R}$ & 100 & 100 & 5 & 2 & 5 & 118 & 0.0 & No \\
\hline 7 & $\mathrm{M}$ & 53 & 15 & $\mathrm{~B}$ & 90 & 100 & 3 & 3 & 3 & 119 & 0.0 & No \\
\hline 8 & $\mathrm{M}$ & 23 & 97 & $\mathrm{~L}$ & 90 & 87 & 9 & 9 & 7 & 97 & 0.0 & Yes \\
\hline 9 & $\mathrm{M}$ & 35 & 81 & $\mathrm{~L}$ & 85 & 79 & 9 & 2 & 5 & 110 & 4.0 & Yes \\
\hline 10 & $\mathrm{~F}$ & 29 & 190 & $\mathrm{R}$ & 80 & 82 & 3 & 1 & 3 & 116 & 0.0 & Yes \\
\hline 11 & $\mathrm{M}$ & 43 & 187 & $\mathrm{R}$ & 95 & 85 & 4 & 1 & 4 & 116 & 0.0 & No \\
\hline 12 & $\mathrm{~F}$ & 20 & 196 & $\mathrm{~L}$ & 100 & 95 & 6 & 4 & 5 & 117 & 0.0 & No \\
\hline 13 & $\mathrm{M}$ & 20 & 121 & $\mathrm{~L}$ & 85 & 89 & 8 & 10 & 9 & 106 & 1.9 & Yes \\
\hline 14 & $\mathrm{M}$ & 24 & 137 & $\mathrm{~L}$ & 80 & 60 & 6 & 4 & 1 & 108 & 3.8 & Yes \\
\hline 15 & $\mathrm{~F}$ & 43 & 42 & $\mathrm{R}$ & 100 & 100 & 9 & 1 & 4 & 102 & 1.4 & No \\
\hline 16 & $\mathrm{~F}$ & 18 & 74 & $\mathrm{R}$ & 60 & 49 & 8 & 8 & 3 & 101 & 5.8 & Yes \\
\hline 17 & $\mathrm{M}$ & 27 & 180 & $\mathrm{~L}$ & 60 & 39 & 7 & 1 & 2 & 100 & 4.0 & Yes \\
\hline 18 & $\mathrm{~F}$ & 44 & 76 & $\mathrm{R}$ & 70 & 64 & 7 & 7 & 1 & 103 & 6.0 & Yes \\
\hline 19 & $\mathrm{M}$ & 38 & 207 & $\mathrm{~L}$ & 50 & 49 & 10 & 10 & 8 & 105 & 4.6 & Yes \\
\hline 20 & M & 63 & 10 & $\mathrm{~L}$ & 45 & 20 & 2 & 2 & 2 & 89 & 7.0 & Yes \\
\hline
\end{tabular}

$F U$ follow-up, $L$ left, $R$ right, OMAS Olerud-Molander Ankle Score, KAFS Karlsson Ankle Function Score, SF-36 Short Form 36, VAS visual analog scale

in our study. Patients apparently benefit from surgery compared with the pre-score; however they do not reach their pre-injury level of activity.

Considering the SF-36 the PCS was $54.2\left(\mathrm{P}_{25}-\mathrm{P}_{75} 45.7-\right.$ 57.2), the MCS was $59.4\left(\mathrm{P}_{25}-\mathrm{P}_{75} 54.2-62.1\right)$ and the total SF-36 score reached $109.5\left(\mathrm{P}_{25}-\mathrm{P}_{75}\right.$ 102.1-117.1). Different notations for the SF-36, applied by Muijs et al. and by Brodsky et al., make comparisons for the quality of life impossible.

The original Castaing procedure has been described only a few times in PubMed. In the large mixed series by Mabit

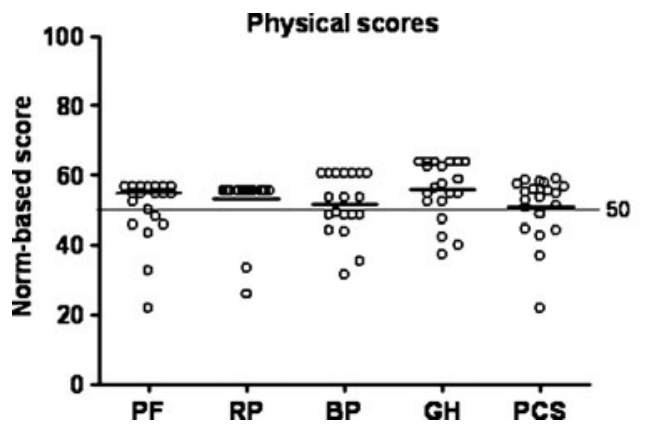

Fig. 3 Norm-based SF-36 physical and mental component scores. The PCS combines the health domains physical functioning $(P F)$, role limitations due to physical health $(R P)$, bodily pain $(B P)$ and general et al. an unknown number of patients was treated with the original Castaing procedure [34]. In this study patients obtained a good to excellent outcome in approximately $70 \%$, which was the poorest outcome of the four groups of reconstructions [34]. This less favourable outcome might be due to a decrease in eversion strength of $8-9 \%$ [43], because the peroneus brevis is one of the stabilisers of the ankle and subtalar joint. Three other series using the Castaing procedure could be identified. In the study by Cañadell et al. 13 patients were followed up for an average of 2.4 years with $92 \%$ of the patients willing to undergo the

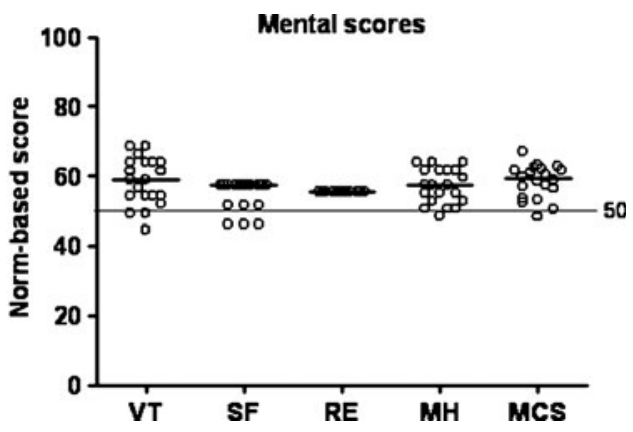

health perceptions $(G H)$. The MCS combines the health domains vitality, energy, or fatigue $(V T)$, social functioning $(S F)$, role limitations due to emotional problems $(R E)$ and general mental health $(M H)$ 
same surgery again [8]. Jarde et al. reviewed 46 patients with an average follow-up of 5.7 years, which obtained a good to excellent outcome in $82 \%$ using the American Orthopaedic Foot and Ankle Society (AOFAS) score [22].

Only a single abstract on ten patients with an unknown duration of follow-up [47], one Italian study on 20 patients with four years follow-up [33] and one series with an unknown number of patients with a mean follow-up of
13 years [34] could be identified in the literature in which the hemi-Castaing was applied. The outcome ranged from an average of 80 points on the AOFAS score [47] and $90 \%$ good to excellent outcome on the AOFAS score [33] to 92.2\% good to excellent outcome on the KAFS [34].

Compared with the anatomical reconstruction our longterm follow-up functional outcome results appear lower. This might be due to worse range of motion in the non-

Table 2 Outcome of various techniques in chronic lateral ankle instability reported in the last decade

\begin{tabular}{|c|c|c|c|c|c|c|c|}
\hline Author & Year & $\begin{array}{l}\text { No. of } \\
\text { patients }\end{array}$ & $\begin{array}{l}\text { Follow-up } \\
\text { (years) }\end{array}$ & Class & Technique & Score & Good+excellent \\
\hline Messer et al. [35] & 2000 & 22 & 34.5 & $\mathrm{AR}$ & Mod. Broström/Gould & Karlsson & 90.9 \\
\hline Paterson et al. [43] & 2000 & 26 & 2 & $\mathrm{AR}$ & Semitendinosis & NA & 81 \\
\hline Krips et al. [31] & 2000 & 185 & 30 & $\mathrm{AR}$ & 3 techniques & Karlsson/Good/Tegner & $70-85$ \\
\hline Krips et al. [30] & 2001 & 25 vs 29 & 12.3 & AR vs NAR & AR vs Evans & Good & 92 vs 69 \\
\hline Nimon et al. [39] & 2001 & 91 & 9.7 & NAR & Evans & Karlsson/Good/AOFAS & 57 \\
\hline Krips et al. [29] & 2002 & 41 vs 36 & 5.4 & AR vs NAR & AR vs Evans & Good/Tegner & 88 vs 58 \\
\hline Krips et al. [28] & 2002 & 54 vs 45 & 20 & AR vs NAR & AR vs Evans & Karlsson/Good & 69.6 vs 33.3 \\
\hline Sugimoto et al. [48] & 2002 & 13 & 2.2 & NAR & Patellar tendon & Good & 100 \\
\hline Järvelä et al. [23] & 2002 & 17 vs 15 & 3.1 & $\mathrm{AR}$ & Karlsson vs AITFL & Karlsson & 93 vs 94 \\
\hline Korkala et al. [27] & 2002 & 25 & 1.7 & NAR & Evans & Good & 80 \\
\hline Cheng and Tho [11] & 2002 & 15 & 3 & NAR & Chrisman-Snooks & Kaikkonen & 93 \\
\hline Jarde et al. [22] & 2002 & 46 & 5.7 & NAR & Castaing & AOFAS & 82 \\
\hline Solakoglu et al. [46] & 2003 & 14 & 1.7 & NAR & Coville & Chrisman-Snooks & 100 \\
\hline Takahashi et al. [49] & 2003 & 13 & 7 & $\mathrm{AR}$ & Ext. dig. longus & Karlsson & 100 \\
\hline Westlin et al. [54] & 2003 & 13 & 10 & NAR & Ext. dig. brevis & Karlsson & 100 \\
\hline Baltopoulus et al. [3] & 2004 & 26 & 8.3 & NAR & Mod. Evans & AOFAS & 93 \\
\hline Chen et al. [10] & 2004 & 56 & 3.1 & $\mathrm{AR}$ & Mod. Broström/Gould & AOFAS & 91.1 \\
\hline Coughlin et al. [14] & 2004 & 29 & 1.9 & $\mathrm{AR}$ & Gracilis & AOFAS/VAS/Karlsson & 100 \\
\hline Schmidt et al. [44] & 2005 & 32 & 3 & $\mathrm{AR}$ & Karlsson & AOFAS & 88 \\
\hline Brodsky et al. [6] & 2005 & 73 & 5.3 & $\mathrm{AR}$ & Broström/Gould & AOFAS/SF-36 PCS & 84 \\
\hline Okazaki et al. [40] & 2005 & 13 & 1.9 & $\mathrm{AR}$ & Broström/periost. & AOFAS & 84.6 \\
\hline Pagenstert et al. [42] & 2005 & 50 & 3.5 & $\mathrm{AR}$ & Plantaris & AOFAS/Karlsson & 96 \\
\hline De Vries et al. [15] & 2005 & 40 & 24 & $\mathrm{AR}$ & Weber & Karlsson/Good & 65 \\
\hline Bell et al. [5] & 2006 & 22 & 26.3 & $\mathrm{AR}$ & Broström & Roos/Good & 91 \\
\hline Ng and Das De [38] & 2007 & 20 & 1 & NAR & Broström/Gould/Evans & Kaikkonen & 100 \\
\hline Jones et al. [24] & 2007 & 4 & 2 & NAR & Polyester tape & NA & 100 \\
\hline Muijs et al. [37] & 2008 & 24 & 13 & $\mathrm{AR}$ & Duquennoy & SF-36/OMAS & 81 \\
\hline Choi et al. [12] & 2008 & 65 & 2.4 & $\mathrm{AR}$ & Mod. Broström & Karlsson & NA \\
\hline Li et al. [32] & 2009 & 52 & 2.4 & $\mathrm{AR}$ & Mod. Broström/Gould & Karlsson/Tegner & NA \\
\hline Ateşalp et al. [2] & 2009 & 9 & NA & NAR & Evans & NA & NA \\
\hline Hua et al. [19] & 2010 & 81 & 2.4 & $\mathrm{AR}$ & Broström/Gould & AOFAS & NA \\
\hline Trc et al. [52] & 2010 & 47 & 3.9 & $\mathrm{AR}$ & Mod. Broström & Good & 100 \\
\hline Mabit et al. [34] & 2010 & 310 & 13 & AR/NAR & Multiple techniques & Karlsson/Good & $71.2-92.2$ \\
\hline Shahrulazua et al. [45] & 2010 & 30 & 0.3 & $\mathrm{AR}$ & Mod. Broström/Gould & Kaikkonen & 100 \\
\hline Morelli et al. [36] & 2010 & 14 & 10.8 & NAR & Hemi-Watson-Jones & AOFAS/Good/Tegner/VAS & 100 \\
\hline Ibrahim et al. [20] & 2010 & 14 & 2.8 & AR & Gracilis & AOFAS/Karlsson/VAS/OMAS & 100 \\
\hline Ahn et al. [1] & 2011 & 24 & 3.1 & AR & Ext. Dig. longus & Karlsson & 95.8 \\
\hline
\end{tabular}

AR anatomical reconstruction, NAR non-anatomical reconstruction, Mod. modified, NA not available, AITFL anterior inferior tibiofibular ligament 
anatomical repair, with half of our patients subjectively complaining of some stiffness in the ankle [30, 34]. Considering stability three patients complained of persistent instability, which has been reported to be lower in the anatomical repairs. In the long term neither repair prevents arthrosis [30].

There has been some contradiction regarding outcome and duration of follow-up [30, 34]. Considering the literature of the last ten years there is an apparent decline in good to excellent outcome with longer follow-up (Table 2). This might also be a reason for fewer good to excellent outcomes in this series.

Even though this study is the largest with the longest follow-up for the hemi-Castaing procedure there are some limitations. The main limitation of this study is its retrospective character, which is related to less reliable data acquisition, especially from the medical charts. Only in a few cases were pre- and postoperative stress radiographs available. As the hemi-Castaing is the sole technique used at our facility we were unable to compare the results with an anatomical repair. However, when comparing the results with the literature, the outcome scores appear lower with fewer good to excellent outcomes observed depending on which outcome scoring system was applied.

We therefore concur with the study by Mabit et al. that the initial surgical treatment of chronic lateral ankle instability should be an anatomical repair with augmentation (i.e. the Broström-Gould technique) and the nonanatomical repair should be reserved for unsuccessful cases or in cases in which no adequate ligamentary remnants are available to suture. The hemi-Castaing technique is a simple procedure, but might prove less satisfactory at the long-term follow-up.

Open Access This article is distributed under the terms of the Creative Commons Attribution Noncommercial License which permits any noncommercial use, distribution, and reproduction in any medium, provided the original author(s) and source are credited.

\section{References}

1. Ahn JH, Choy WS, Kim HY (2011) Reconstruction of the lateral ankle ligament with a long extensor tendon graft of the fourth toe. Am J Sports Med 30:637-644

2. Ateşalp S, Demiralp B, Ozkal UB, Uğurlu M, Bozkurt M, Başbozkurt M (2009) Modified Evans technique improves plantar pressure distribution in lateral ankle instability. Eklem Hastalik Cerrahisi 20:41-46

3. Baltopoulos P, Tzagarakis GP, Kaseta MA (2004) Midterm results of a modified Evans repair for chronic lateral ankle instability. Clin Orthop Relat Res 422:180-185

4. Baumhauer JF, O'Brien T (2002) Surgical considerations in the treatment of ankle instability. J Athl Train 37:458-462
5. Bell SJ, Mologne TS, Sitler DF, Cox JS (2006) Twenty-six-year results after Broström procedure for chronic lateral ankle instability. Am J Sports Med 34:975-978

6. Brodsky AR, O’Malley MJ, Bohne WH, Deland JA, Kennedy JG (2005) An analysis of outcome measures following the BroströmGould procedure for chronic lateral ankle instability. Foot Ankle Int 26:816-819

7. Broström L (1966) Sprained ankles. VI. Surgical treatment of "chronic" ligament ruptures. Acta Chir Scand 132:551-565

8. Cañadell JM, Valenti JR, Martinez A, de Pablos J, Villas C (1982) Chronic lateral instability of the ankle. Arch Orthop Trauma Surg 99:189-193

9. Castaing J, Falaise B, Burdin P (1984) Ligamentoplasty using the peroneus brevis in the treatment of chronic instabilities of the ankle. Long-term review. Rev Chir Orthop Reparatrice Appar Mot 70:653-656

10. Chen CY, Huang PJ, Kao KF, Chen JC, Cheng YM, Chiang HC, Lin CY (2004) Surgical reconstruction for chronic lateral instability of the ankle. Injury 35:809-813

11. Cheng M, Tho KS (2002) Chrisman-Snook ankle ligament reconstruction outcomes-a local experience. Singapore Med J 43:605-609

12. Choi WJ, Lee JW, Han SH, Kim BS, Lee SK (2008) Chronic lateral ankle instability: the effect of intra-articular lesions on clinical outcome. Am J Sports Med 36:2167-2172

13. Coughlin MJ, Matt V, Schenck RC Jr (2002) Augmented lateral ankle reconstruction using a free gracilis graft. Orthopedics 25:31-35

14. Craviari T, Besse JL, Curvale G, Maestro M, Tourné Y (2003) Evaluation of a long-distance data transmission network in foot and ankle surgery. Rev Chir Orthop Reparatrice Appar Mot 89:433-442

15. De Vries J, Struijs PA, Raaymakers EL, Marti RK (2005) Longterm results of the Weber operation for chronic ankle instability: 37 patients followed for 20-30 years. Acta Orthop 76:891-898

16. DiGiovanni BF, Partal G, Baumhauer JF (2004) Acute ankle injury and chronic lateral instability in the athlete. Clin Sports Med 23:1-19

17. DiGiovanni CW, Brodsky A (2006) Current concepts: lateral ankle instability. Foot Ankle Int 27:854-866

18. Greer Richardson E (2001) Chronic lateral ligament laxity: reconstruction by the Chrisman-Snook and Watson-Jones peroneus brevis transfers and the modified Broström procedure. Oper Tech Sports Med 9:26-31

19. Hua Y, Chen S, Li Y, Chen J, Li H (2010) Combination of modified Broström procedure with ankle arthroscopy for chronic ankle instability accompanied by intra-articular symptoms. Arthroscopy 26:524-528

20. Ibrahim SA, Hamido F, Al Misfer AK et al (2010) Anatomical reconstruction of the lateral ligaments using gracillis tendon in chronic ankle instability; a new technique. Foot Ankle Surg. Epub ahead of print

21. Jarde O, Havet E, Gabrion A, Meire P, Vives P (1999) Long-term outcome following surgical repair of ruptures of the fibular collateral ligament of the ankle. A report of 50 cases. Acta Orthop Belg 65:340-345

22. Jarde O, Duboille G, Abi-Raad G, Boulu G, Massy S (2002) Ankle instability with involvement of the subtalar joint demonstrated by MRI. Results with the Castaing procedure in 45 cases. Acta Orthop Belg 68:515-528

23. Järvelä $T$, Weitz $H$, Järvelä $K$, Alavaikko A (2002) A novel reconstruction technique for chronic lateral ankle instability: comparison to primary repair. Int Orthop 26:314-317

24. Jones AP, Sidhom S, Sefton G (2007) A minimally invasive surgical technique for augmented reconstruction of the lateral ankle ligaments with woven polyester tape. J Foot Ankle Surg $46: 416-423$ 
25. Karlsson J, Bergsten T, Lansinger O, Peterson L (1988) Lateral instability of the ankle treated by the Evans procedure. A longterm clinical and radiological follow-up. J Bone Joint Surg Br 70:476-480

26. Kerkhoffs GM, Handoll HH, de Bie R et al (2007) Surgical versus conservative treatment for acute injuries of the lateral ligament complex of the ankle in adults. Cochrane Database Syst Rev: CD000380

27. Korkala O, Sorvali T, Niskanen R et al (2002) Twenty-year results of the Evans operation for lateral instability of the ankle. Clin Orthop Relat Res 405:195-198

28. Krips R, Brandsson S, Swensson C, van Dijk CN, Karlsson J (2002) Anatomical reconstruction and Evans tenodesis of the lateral ligaments of the ankle. Clinical and radiological findings after follow-up for 15 to 30 years. J Bone Joint Surg Br 84:232-236

29. Krips R, van Dijk CN, Lehtonen H, Halasi T, Moyen B, Karlsson J (2002) Sports activity level after surgical treatment for chronic anterolateral ankle instability. A multicenter study. Am J Sports Med 30:13-19

30. Krips R, van Dijk CN, Halasi PT, Lehtonen H, Corradini C, Moyen B, Karlsson J (2001) Long-term outcome of anatomical reconstruction versus tenodesis for the treatment of chronic anterolateral instability of the ankle joint: a multicenter study. Foot Ankle Int 22:415-421

31. Krips R, van Dijk CN, Halasi T, Lehtonen H, Moyen B, Lanzetta A, Farkas T, Karlsson J (2000) Anatomical reconstruction versus tenodesis for the treatment of chronic anterolateral instability of the ankle joint: a 2- to 10-year follow-up, multicenter study. Knee Surg Sports Traumatol Arthrosc 8:173-179

32. Li X, Lin TJ, Busconi BD (2009) Treatment of chronic lateral ankle instability: a modified Broström technique using three suture anchors. J Orthop Surg Res 4:41

33. Lorenzo G, Calafiore V (2009) Trattamento chirurgico Secondo Castaing nelle instabilita laterali di caviglia. Acta Orthop Ital 34:11-14

34. Mabit C, Tourné Y, Besse JL, Bonnel F, Toullec E, Giraud F, Proust J, Khiami F, Chaussard C, Genty C et al (2010) Chronic lateral ankle instability surgical repairs: the long term prospective. Orthop Traumatol Surg Res 96:417-423

35. Messer TM, Cummins CA, Ahn J, Kelikian AS (2000) Outcome of the modified Broström procedure for chronic lateral ankle instability using suture anchors. Foot Ankle Int 21:996-1003

36. Morelli F, Perugia D, Vadalà A et al (2010) Modified WatsonJones technique for chronic lateral ankle instability in athletes: clinical and radiological mid- to long-term follow-up. Foot Ankle Surg. Epub ahead of print

37. Muijs SP, Dijkstra PD, Bos CF (2008) Clinical outcome after anatomical reconstruction of the lateral ankle ligaments using the Duquennoy technique in chronic lateral instability of the ankle: a long-term follow-up study. J Bone Joint Surg Br 90:50-56

38. Ng ZD, De Das S (2007) Modified Brostrom-Evans-Gould technique for recurrent lateral ankle ligament instability. J Orthop Surg (Hong Kong) 15:306-310
39. Nimon GA, Dobson PJ, Angel KR, Lewis PL, Stevenson TM (2001) A long-term review of a modified Evans procedure. J Bone Joint Surg Br 83:14-18

40. Okazaki K, Miyagi S, Tokunaga J (2005) Anatomic reconstruction of the lateral ligament of the ankle using a periosteal flap from the fibula. Tech Foot Ankle Surg 4:98-103

41. Olerud C, Molander H (1984) A scoring scale for symptom evaluation after ankle fracture. Arch Orthop Trauma Surg 103:190-194

42. Pagenstert GI, Hintermann B, Knupp M (2006) Operative management of chronic ankle instability: plantaris graft. Foot Ankle Clin 11:567-583

43. Paterson R, Cohen B, Taylor D, Bourne A, Black J (2000) Reconstruction of the lateral ligaments of the ankle using semitendinosis graft. Foot Ankle Int 21:413-419

44. Schmidt R, Benesch S, Friemert B, Herbst A, Claes L, Gerngross $\mathrm{H}$ (2005) Anatomical repair of lateral ligaments in patients with chronic ankle instability. Knee Surg Sports Traumatol Arthrosc 13:231-237

45. Shahrulazua A, Ariff Sukimin MS, Tengku Muzaffar TM, Yusof MI (2010) Early functional outcome of a modified BrostromGould surgery using bioabsorbable suture anchor for chronic lateral ankle instability. Singapore Med J 51:235-241

46. Solakoglu C, Kiral A, Pehlivan O, Akmaz I, Arpacioglu MO, Kaplan H (2003) Late-term reconstruction of lateral ankle ligaments using a split peroneus brevis tendon graft (Colville's technique) in patients with chronic lateral instability of the ankle. Int Orthop 27:223-227

47. Solana J, Pons M, Guinot C, Viladot R (2005) Tenodesis of the peroneus brevis and ligament capsuloplasty in chronic ankle instability. In: SECOT, Sociedad Espanola de Cirugia Ortopedica y Traumatologia. Seville, Spain

48. Sugimoto K, Takakura Y, Samoto N et al (2002) Subtalar arthrography in recurrent instability of the ankle. Clin Orthop Relat Res 394:169-176

49. Takahashi T, Nakahira M, Kaho K, Kawakami T (2003) Anatomical reconstruction of chronic lateral ligament injury of the ankle using pedicle tendon of the extensor digitorum longus. Arch Orthop Trauma Surg 123:175-179

50. Tegner Y, Lysholm J (1985) Rating systems in the evaluation of knee ligament injuries. Clin Orthop Relat Res 198:43-49

51. Tourné Y, Besse JL, Mabit C et al (2010) Chronic ankle instability. Which tests to assess the lesions? Which therapeutic options? Orthop Traumatol Surg Res 96:433-446

52. Trc T, Handl M, Havlas V (2010) The anterior talo-fibular ligament reconstruction in surgical treatment of chronic lateral ankle instability. Int Orthop 34:991-996

53. Ware JE Jr, Sherbourne CD (1992) The MOS 36-item short-form health survey (SF-36). I. Conceptual framework and item selection. Med Care 30:473-483

54. Westlin NE, Vogler HW, Albertsson MP, Arvidsson T, Montgomery F (2003) Treatment of lateral ankle instability with transfer of the extensor digitorum brevis muscle. J Foot Ankle Surg 42:183-192 